\title{
Treatment of male infertility due to spinal cord injury using rectal probe electroejaculation: the Israeli experience
}

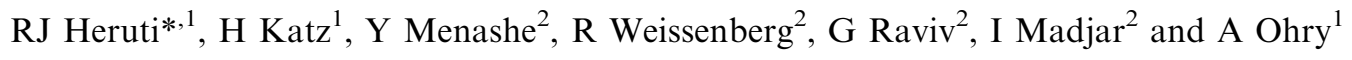 \\ ${ }^{1}$ Department of Neuro-Rehabilitation, Sheba Medical Center, Tel-Hashomer 52621, Israel; ${ }^{2}$ Andrology Unit, Sheba \\ Medical Center, Tel-Hashomer 52621, Israel
}

\begin{abstract}
Study design: Male infertility caused by anejaculation is common among patients with spinal cord injury (SCIP). The fertility options for SCIP have improved impressively over the past 10 years. We present the Israeli experience in the treatment of infertility in a large series of SCIP. The issues which are addressed include the treatment of ejaculatory dysfunction, seminal quality and fertility management in SCIP.

Setting: Sexual rehabilitation clinic, Neuro-Rehabilitation department, Sheba Medical Center, Israel.

Methods: Between June 1992 and May 1998, a total of 84 consecutive SCIP were treated in our clinic with electro-ejaculation (EEJ), representing a sample of the SCIP population, composed mostly of young men traumatically injured. The patients have sustained different levels and completeness of spinal injury. Among the patients 33 were interested in achieving pregnancy $(39.3 \%)$, while the rest were interested in determining fertility potential for family. With EEJ, a low-current stimulation of the ejaculatory organs via a rectal probe is done. The collected semen is used for fertility determination or for fertilization.

Results: Eighty-four patients were treated by EEJ. Mean age was 31.3 and mean age at injury was 21.7. There were 29 cervical, 50 thoracic and five lumbar lesions. Sixty-three had complete injury (ASIA A) and 21 incomplete (ASIA B -15, ASIC C -5, ASIA D -1). Fifty-nine had upper motor neuron lesions, and 25 had lower motor neuron. A total of 355 stimulations were performed. Ejaculate was obtained in all patients in 350 stimulations $(98.6 \%)$, and sperm was present in 74 patients $(88.1 \%)$ in 296 of the stimulations $(83.4 \%)$. Fairly good numbers of spermatozoa were obtained, whereas sperm motility and morphology of spermatozoa were low in most cases. A significant difference in sperm count, motility and morphology was noted between antegrade and retrograde samples. No significant improvement in sperm quality after four repeated consecutive stimulations was noted in 38 SCIP. Side effects were minor and encountered in 16 patients $(19.1 \%)$. Out of 33 couples who wished to achieve pregnancy, 26 reached the stage of insemination. Four pregnancies were achieved after 33 cycles of InUterine-Insemination (pregnancy rate $28.6 \%$ per couple), and 15 after 68 cycles of In-VitroFertilization (micromanipulation) (pregnancy rate of $68.75 \%$ per couple). In all, of 101 conception attempts 23 were successful, resulting in pregnancies in 18 couples, and accounting for an overall pregnancy rate of $70 \%$ per couple.

Conclusion: The high percentage of pregnancies imply that, despite the typically poor sperm motility noted in EEJ, rectal probe EEJ combined with assisted reproductive techniques, and performed by a team approach, is an efficient and safe technique for treating infertility among SCIP.

Spinal Cord (2001) 39, $168-175$
\end{abstract}

Keywords: spinal cord injury; sexuality; fertility; electroejaculation

\section{Introduction}

Male infertility caused by anejaculation is a common phenomenon after spinal cord injury (SCI). ${ }^{1}$ Fortunately, the fertility options for patients with spinal

*Correspondence: R Heruti, Mandel 1/13 st., Ramat-Gan 52287, Israel cord injury (SCIP) have improved impressively over the past 10 years. ${ }^{2}$ It has been found that the rehabilitation process is more efficient when attention is given to the sexual as well as the physical aspects of the disability. ${ }^{3}$ Most SCIP suffer from infertility, mainly due to erectile and/or ejaculatory dysfunc- 
tion. Approximately $54 \%$ to $82 \%$ of these individuals can maintain full or partial erection, but only $3 \%$ to $15 \%$ can demonstrate ejaculatory capability., Antegrade ejaculation has been reported in $5 \%$ of patients with complete upper motor neuron lesions (UMN), $18 \%$ with complete lower motor neuron lesions (LMN), 32\% with incomplete UMN and $70 \%$ with incomplete LMN., ${ }^{2,3}$ Those ejaculations usually present low sperm quality ${ }^{5,6}$ and signs of infection. ${ }^{7}$ Retrograde ejaculation is common, due to sympathetic denervation of the bladder neck. The ejaculatory failure has prompted the development of various methods for ejaculation procurement, such as intrathecal injection of neostigmine, ${ }^{8}$ subcutaneous physostigmine, ${ }^{9}$ microsurgical aspiration techniques of sperm from epididymis and testes, ${ }_{10}^{10}$ direct stimulation of the hypogastric nerve, ${ }^{11}$ penile vibratory stimulation (PVS) ${ }^{3,92-14}$ and electroejaculation (EEJ). ${ }^{13-21}$

With EEJ, a low-current stimulation of the ejaculatory organs via a rectal probe is done, causing induction of seminal emission. ${ }^{13-21}$ Improvement in the stimulator and the techniques in the past 15 years have established EEJ as a simple and promising method to induce ejaculation in anejaculatory men. Currently it is the most widely used technique of semen procurement in anejaculate SCIP, ${ }^{18}$ with a success rate of approximately $60 \%$ to $90 \%$ varying among different centers. ${ }^{13-21}$ In general these electroejaculates exhibit high sperm counts, but low motility and poor sperm function. $2,5,6,13,14,18,19$

Semen collected by EEJ can be used in conjunction with Intra Uterine Insemination (IUI) or In Vitro Fertilization (IVF). ${ }^{15-21}$ The use of intra cytoplasmatic sperm injection (ICSI) seems to be promising. ${ }^{14,18,22}$ Pregnancies using electroejaculates in SCIP have been documented since 1975 in the form of case reports and small series. ${ }^{8,14,15,17,20,23-25}$ Although results are encouraging, pregnancy rates cannot be accurately estimated, because of lack of large series in the literature. This study attempts to address this issue, presenting a large series.

During 1992 a SCIP fertility clinic was established at the neurological rehabilitation department, Sheba Medical Center, for SCIP who wish to father a child or to determine fertility potential. An inter-disciplinary team approach, ${ }^{26}$ comprised of a physiatrist, andrologist, gynecologist, nurse, sperm-laboratory specialist and a social worker, was adopted. This staff is an integral part of the rehabilitation center staff, and engaged in other medical activities. The fertility service is an integral part of the gynecologyobstetric wing. We present the experience of our clinic in a large series of patients. We document the success rates of EEJ in 84 consecutive SCIP. A subgroup of 33 men and their spouses desired conception and progressed to actual attempts. Interventions included IUI, IVF, and IVF/ICSI. Success rates were documented. Few of the issues addressed include the treatment of ejaculatory dysfunction, seminal quality and fertility management in SCIP. We hope this paper will encourage the continued development of properly funded spinal fertility services around the world.

\section{Subjects and methods}

\section{Subjects}

In the 6 years between June 1992 and May 1998, a total of 84 consecutive SCIP were treated in the sexual rehabilitation clinic with EEJ, representing a sample of the SCIP population, composed mostly of young men traumatically injured. This group included men with spinal lesions extending from $\mathrm{C} 2$ to L2. Among the patients, 33 were interested in achieving pregnancy $(39.3 \%)$, while the rest were interested in determining fertility potential for family planning and/or producing sperm for frozen preservation. All patients were in stable medical condition and had been anejaculatory since the injury.

All patients were referred from various community services, which provided them with regular financial coverage for the process. In Israel all the population is insured according to their health care system. This coverage includes for instance US\$750 for the EEJ procedure (including semen analysis). All patients underwent an evaluation process consisting of several procedures. Medical history was reviewed, particularly concerning level of the spinal cord lesion, completeness of motor and sensory deficits, elapsed time since the injury, autonomic dysreflexia, presence or absence of spasticity, medications, the method of bladder management, and the patient's history of urinary tract infection, urinary stones and epididymitis. Patients were asked about the erectile and ejaculatory function during masturbation and intercourse, previous sexual function, fertility and changes since the injury. A physical examination was performed with an emphasis on the neurologic and urologic status. If necessary, urodynamic studies were done to determine urologic condition. All patients had baseline laboratory evaluations including blood biochemistry, a complete blood count, and hormonal profile, including follicle-stimulating hormone (FSH), luteinizing hormone $(\mathrm{LH})$, testosterone, and prolactin. Urinalysis, urine culture and sensitivity, urine examination for sperm presence after masturbation was undertaken. Subjects with a urinary tract infection were treated with antibiotics prior to each attempt of electrical stimulation.

\section{Rectal probe}

Following evaluation, 84 SCIP who were unable to produce sperm by masturbation, were referred to EEJ. All patients gave their informed consent with a full understanding of the procedure and the possible side effects before each attempt. EEJ was performed using 
Seager's instrument Model 14 electrical stimulator (G\&S Instrument Co., Duncanaville, TX, USA), which is approved by the FDA. It consists of a probe inserted into the rectum. The probe includes transmitting an electrical current only to the desired part of the rectum, and not in a dispersion of $360^{\circ}$, that could affect the entire rectum. The appliance consists of probes in various sizes.

Bowel preparation was carried out on the morning of the procedure. The bladder was emptied via a plastic catheter, washed with sterile saline solution, and $20 \mathrm{cc}$ Ham's F-10 solution was instilled. ${ }^{27}$ After an anoscopic examination of the rectal mucosa, an appropriate-sized lubricated probe was inserted into the rectum to the appropriate depth with the patient placed in a left lateral decubitus position on a standard examination table. If the anal sphincter was tight, a gentle manual movement of a finger achieved relaxation. The electrodes were faced anteriorly in the proximity of the prostate and the voltage was promptly increased to $7.5-20 \mathrm{~V}$ for duration of 4$5 \mathrm{~s}$, resulting in an antegrade and/or retrograde ejaculate in most cases. If ejaculate was not achieved, up to a maximum of three stimulations of 4-5 s were administered. Maximal voltage never exceeded $20 \mathrm{~V}$ while maximal current never increased above $300 \mathrm{~mA}$. Rectal temperature was monitored by a thermistor on the probe surface. Simultaneously, the urethra was milked forward to encourage antegrade emission. The bladder was re-catheterized in the end of the procedure to capture any semen in the bladder or prostatic urethra. Antegrade ejaculate and bladder content were collected in two sterile nonspermicidal containers and taken to the laboratory for analysis. Anoscopy was repeated to observe any change in rectal mucosa.

Blood pressure and heart rate were monitored throughout the procedure every 1 or $2 \mathrm{~min}$. Pretreatment with calcium channel blockers to prevent autonomic dysreflexia was rarely needed, since blood pressure rapidly returned to normal after withdrawal of stimulation. Stimulation was terminated if the systolic blood pressure exceeded $180 \mathrm{mmHg}$, diastolic exceeded $120 \mathrm{mmHg}$, rectal temperature exceeded $39^{\circ} \mathrm{C}$ or if any side effects occurred. In most cases, Diazepam in a dose of up to $10 \mathrm{mg}$ was given intravenously in order to lower spasticity, and patient's anxiety and restlessness. If local pain at the stimulation site was noted, intravenous analgesia with a combination of meperidine and diazepam was given. Full sensation of the genital region or pain after intravenous analgesia mandated general anesthesia.

One or more stimulations were performed for preliminary analysis of the baseline semen parameters. Once a reasonable potential for impregnation was established, cryopreservation of sperm or insemination of the partner is planned. With failure to achieve sperm with EEJ, the patient is referred to testicular sperm aspiration.

\section{Analysis of semen}

The specimens were analyzed using World Health Organization criteria. $^{28}$ Semen volume, total sperm count, motility, total motile sperm count, and morphology were included in the data analysis. The retrograde fraction was centrifuged, suspended in 0.5 cc Ham's F-10 solution, and analyzed for presence of sperm and motility.

\section{Conception techniques}

Thirty-three couples wishing fertility were treated simultaneously at the clinic. The treatment of each couple was individualized based on results of sperm analysis and concomitant female factors, although emphasis was made to start with the least invasive procedure. All spouses were fully evaluated to detect the presence and direct the treatment of any coexistent female factors. The collected semen was prepared by filtration with mini-percol in three gradients. We also induced pentoxy-phyllin and deoxy-adenosine to accelerate sperm motility. The sperm was then used in various assisted reproductive techniques according to sperm quality.

For couples with sperm analysis above 10 million sperm per $\mathrm{cc}^{29}$ and normal female evaluation, IUI was used as first line of treatment. If three cycles of treatment have failed, the patients were referred to IVF. Those patients with less than 10 million sperms per cc or mechanical problems of their female partner were sent primarily for IVF treatment (Figure 1). For all patients who reach the IVF we use ICSI, as this method gives more success rates with low sperm quality. ${ }^{22}$ Female partners were super-ovulated to improve the pregnancy rate.

\section{Statistics}

Paired comparison $t$-test was used to compare the difference between antegrade and retrograde ejaculate parameters. Results are expressed as means with standard deviations.

\section{SMC TREATMENT MODEL}

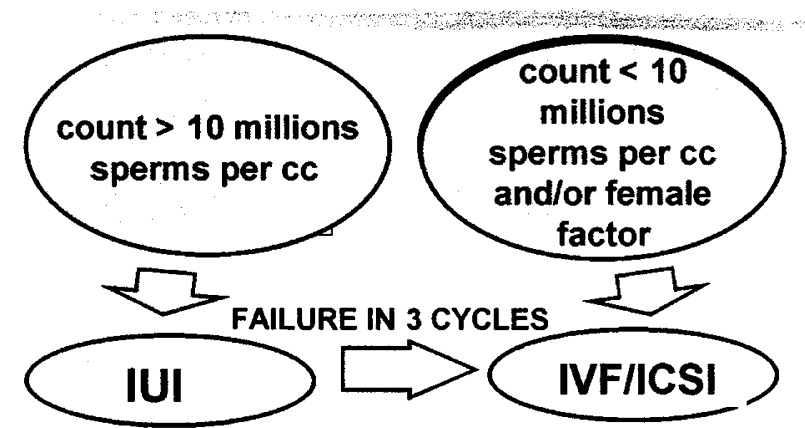

Figure 1 The SMC fertility model for SCIP 


\section{Results}

\section{Demographic data}

Eighty-four patients were treated by EEJ until 31/5/98. Among the patients 37 were married, 12 had a significant other, and the rest were singles. The mean age was $31.3 \pm 6.9$ years (Table 1), ranging from 19 to 45. Mean age at injury was $21.7 \pm 4.3$ years, ranging from 6 to 36 years. Prior to consulting the clinic the mean duration of injury was $7.1 \pm 7.1$ years, ranging from 4 months to 34 years. Twenty-six patients $(30.9 \%)$ were injured 1 year or less before the procedure was performed, while 37 (44\%) were injured 5 years or more from the injury. There were 29 cervical, 50 thoracic and five lumbar lesions in the study group. There were 63 complete (American Spinal Injury Association (ASIA) A) and 21 incomplete (ASIA B -15, ASIA C -5, ASIA D -1) lesions. There were 59 patients with UMN, and 25 with LMN. Forty-one patients had spinal levels at T6 or above. The type of bladder according to urodynamic investigations, and the manner of bladder management are given in Table 1.

\section{Electroejaculation procedures}

A total of 355 stimulations were performed until $31 / 5$ / 98. Twenty-five SCIP had a single stimulation, two had fifteen stimulations, and the others had 2-14 stimulations.

Table 1 Patients' characteristics $(n=84)$

\begin{tabular}{|c|c|c|c|}
\hline Age (years) & $31.3 \pm 6.9$ & \multicolumn{2}{|c|}{ range 19 to 45} \\
\hline $\begin{array}{l}\text { Age at injury } \\
\text { (years) }\end{array}$ & $21.7 \pm 4.3$ & \multicolumn{2}{|c|}{ range 6 to 36} \\
\hline $\begin{array}{l}\text { Duration of } \\
\text { injury (years) }\end{array}$ & $7.1 \pm 7.1$ & \multicolumn{2}{|c|}{ range 4 months to 34 years } \\
\hline Level of & Cervical & \multicolumn{2}{|l|}{$29(34.5 \%)$} \\
\hline injury & Thoracic & \multicolumn{2}{|l|}{$50(59.5 \%)$} \\
\hline \multirow{4}{*}{$\begin{array}{l}\text { Severity of } \\
\text { injury }\end{array}$} & Complete & ASIA $^{\mathrm{a}} \mathrm{A}$ & $63(75 \%)$ \\
\hline & Incomplete & ASIA B & $15(17.9 \%)$ \\
\hline & & ASIA C & $5(5.9 \%)$ \\
\hline & & ASIA D & $1(1.4 \%)$ \\
\hline \multirow[t]{2}{*}{ Type of injury } & & $\mathrm{UMN}^{\mathrm{b}}$ & $59(70.2 \%)$ \\
\hline & & \multirow[t]{2}{*}{$\mathrm{LMN}^{\mathrm{c}}$} & $25(29.8 \%)$ \\
\hline T6 and above & & & $41(48.8 \%)$ \\
\hline \multirow{3}{*}{$\begin{array}{l}\text { Type of } \\
\text { bladder }\end{array}$} & \multicolumn{2}{|c|}{ Hyperreflexic bladder } & $56(66.7 \%)$ \\
\hline & \multicolumn{2}{|c|}{ Atonic bladder } & $22(26.2 \%)$ \\
\hline & \multicolumn{2}{|c|}{ Augmentation cytoplasty } & $6(7.1 \%)$ \\
\hline \multirow[t]{5}{*}{$\begin{array}{l}\text { Bladder } \\
\text { management }\end{array}$} & \multicolumn{2}{|c|}{$\begin{array}{l}\text { Intermittent self } \\
\text { catheterization }\end{array}$} & $46(54.8 \%)$ \\
\hline & \multicolumn{2}{|c|}{ Reflex voiding } & $15(17.9 \%)$ \\
\hline & \multicolumn{2}{|c|}{ Crede maneuver } & $9(10.7 \%)$ \\
\hline & \multicolumn{2}{|c|}{ Indwelling catheter } & $3(3.6 \%)$ \\
\hline & \multicolumn{2}{|l|}{ Other } & $11(13.1 \%)$ \\
\hline
\end{tabular}

${ }^{\mathrm{a} A S I A}$, American Spinal Injury Association; ${ }^{\mathrm{b}} \mathrm{UMN}$, Upper Motor Neuron lesion; ${ }^{\mathrm{c}} \mathrm{LMN}$, Lower Motor Neuron lesion
Side effects

These were encountered in 16 patients $(19.1 \%)$, including abdominal pain or spasm in 17 stimulations, raised blood pressure in 15 stimulations, three cases of increased spasm, and one case of syncope. Abdominal pain and spasm resolved and blood pressure returned to normal after withdrawal of the stimulation. No treatment was needed. No complications were encountered.

\section{Semen analysis}

Ejaculate, whether antegrade or retrograde, was obtained in all patients, and in 350 stimulations $(98.6 \%)$ (Table 2). In 296 of the stimulations $(83.4 \%)$ in 74 patients $(88.1 \%)$, sperm was present in the ejaculate.

Ejaculation success rate by EEJ as reported in the literature varies a great deal, largely because there is no strict definition for success. We adopted Ohl and associates' definition, ${ }^{29}$ stating that a procedure is successful if more than a total of 10 million spermatozoa, of which 1 million were motile, were obtained. This is the minimal criterion for use in IUI. By this strict criteria EEJ was successful in only 124 $(34.9 \%)$ of the stimulations and in $46(54.8 \%)$ of the patients.

Semen evaluation performed according to WHO criteria, ${ }^{27}$ showed a large intersubject variation (Table 3). Fairly good numbers of spermatozoa were obtained, whereas sperm motility and morphology of spermatozoa were low in most cases. The mean antegrade semen parameters from 298 samples were: volume $1.44 \mathrm{cc}$ (range $0.1-8$ ); mean sperm concentration 31.5 million sperms/cc (range $0-340$ ); total sperm 57.9 million sperms (range $0-1020$ ); motility $7.9 \%$ (range $0-70$ ); total motile sperm 4.8 million (range $0-$ 111 ); and $10.5 \%$ normal zoa (range $0-58$ ). The mean retrograde semen parameters from 252 samples were: total sperm 12.3 million sperms (range $0-450$ ); motility $4.2 \%$ (range $0-84$ ); total motile sperm 0.6 (range $0-36.3$ ) and 5.3\% normal zoa (range $0-54$ ). Sperm count, motility and morphology were significantly higher in the antegrade sample $(P>0.001)$ compared to the retrograde. No significance in success rate was found between patients with LMN

Table 2 Total ejaculate, sperm presence and sperm quality in 355 electroejaculations procedures and the distribution according to type of emission produced (antegrade, retrograde and combination)

\begin{tabular}{lccccc}
\hline Electroejaculations $(\mathrm{n}=355)$ & & $\begin{array}{c}\text { Combina- } \\
\text { tion }\end{array}$ & $\begin{array}{c}\text { Ante- } \\
\text { grade }\end{array}$ & $\begin{array}{c}\text { Retro- } \\
\text { grade }\end{array}$ \\
& Total & $\%$ & 217 & 86 & 47 \\
\hline Ejaculation & 350 & 98.6 & 217 & 75 & 45 \\
Sperm present & 296 & 83.4 & 176 & 26 & 5 \\
Viable sperm (27) & 124 & 34.9 & 93 &
\end{tabular}


Table 3 Semen parameters in electroejaculates-comparison between antegrade and retrograde emissions

\begin{tabular}{|c|c|c|c|}
\hline & $\begin{array}{c}\text { Antegrade } \\
\text { (298 stimulations; } \\
77 \text { patients) } \\
\text { Mean } \pm \text { SD (Min-Max) }\end{array}$ & $\begin{array}{c}\text { Retrograde } \\
\text { (252 stimulations; } \\
77 \text { patients) } \\
\text { Mean } \pm S D(\text { Min-Max) }\end{array}$ & $\mathrm{P}$ \\
\hline Semen volume (cc) & $1.44 \pm 1.3 \quad(0.1-8)$ & $\mathrm{NA}^{\mathrm{a}}$ & \\
\hline Sperm concentration $\left(\times 10^{6} / \mathrm{cc}\right)$ & $31.5 \pm 45.5(0-340)$ & NA & \\
\hline Total sperm count $\left(\times 10^{6} / \mathrm{cc}\right)$ & $57.9 \pm 86.3(0-1020)$ & $12.3 \pm 33.4(0-450)$ & 0.0001 \\
\hline Sperm motility $(\%)$ & $7.9 \pm 13.9(0-70)$ & $4.2 \pm 11.8(0-84)$ & 0.001 \\
\hline Total motile sperms $\left(\times 10^{6}\right)$ & $4.8 \pm 14.6(0-111)$ & $0.6 \pm 2.7 \quad(0-36.3)$ & 0.016 \\
\hline Motility grade $(0-4)$ & $2.1 \pm 0.8 \quad(0-3.5)$ & $1.9 \pm 0.9 \quad(0-3.5)$ & 0.925 \\
\hline Sperm morphology (\% normal zoa) & $10.5 \pm 12.8(0-58)$ & $5.3 \pm 8.0 \quad(0-54)$ & 0.001 \\
\hline
\end{tabular}

${ }^{\mathrm{a}} \mathrm{NA}$, not applicable

and UMN, concerning ejaculation rate or semen quality.

Can repeated stimulations improve semen quality? As mentioned above, 38 patients had more than three stimulations. No significant improvement was seen concerning sperm concentration, and total number of motile sperm (representing sperm quality) between four consecutive antegrade ejaculations of these 38 SCIP.

\section{Pregnancy achievement}

Thirty-three couples wished to achieve pregnancy. The mean age of the males was 33.2 years (range 24-45), and of the females 28.2 years (range 23-39). Twenty patients had UMN lesions, among which the lesion was complete in 19 patients, while one had an incomplete lesion (ASIA B). Thirteen patients had LMN lesions, seven with complete lesions and six with incomplete lesions (ASIA B -3, ASIA C -2, ASIA D -1). Eight had cervical lesions and the rest dorso-lumbar lesions.

Out of the 33 couples, 26 had reached the stage of insemination (Table 4) (one couple is still under evaluation; four did not have sperm on EEJ and were referred to sperm aspiration from the proximal vas deferens or testis; one couple dropped out due to personal reason, and one was found to have germinal failure). Of these, 15 couples had suitable semen and underwent IUI (Table 5). Thirty-three cycles of IUIs were performed, resulting in five normal term infants in four couples (Table 4; NB, KS, HH, FE), and one spontaneous abortion (in a couple that eventually achieved pregnancy on IUI (KS)). Pregnancy rate $33.3 \%$ per couple. One couple is still during the process of IUI (RY). Five couples went on to IVF/ ICSI before terminating three trials of IUIs as suggested, at their own request (LS, AA, MZ, YO, $\mathrm{KI}$ ). One couple wished to continue with IUI even after three failures (NI).

Couples that have reached the stage of IVF/ICSI included nine couples after failure of IUI and eleven couples directly (due to low sperm quality). In this group, 20 couples underwent at least one cycle of sperm injection (IVF/ICSI) (1-7 cycles, mean 3.45), comprising a total of 68 cycles (Tables 4 and 5). Eighteen pregnancies have resulted, from which 21 normal term infants were born to date to 14 couples. Three spontaneous abortions occurred in two couples (Table 4; GR, MZ) (that eventually had normal term infants). One couple had two successful pregnancies (LS). Seven couples are still during the process (for one couple (SA) it is the second round) and one couple is in preparation for ICSI after failed IUI (NI). With the use of IVF/ICSI, 14 couples have achieved pregnancy to date, accounting for a pregnancy rate of $70 \%$ per couple.

In all, of 101 conception attempts 23 were successful, resulting in pregnancies in 18 couples, and accounting for an overall pregnancy rate of $69.2 \%$ per couple (Tables 4 and 5). Twenty-six healthy babies (five couples had twins and one had triplets) have now been born to 18 couples out of the original 26. There were four abortions, one after IUI and three after IVF/ICSI, but all couples that had abortions, eventually conceived. It is worth mentioning, that one of the babies was the first one in the world to be born after an augmentation cystoplasty (Table 4; LS). Another baby was born 38 years after his father was injured (the father was 6 years old when injured) (HS).

\section{Discussion}

In our series and in other studies, semen analysis shows a large intersubject variation: semen count is usually normal, while sperm motility and the morphology of spermatozoa were in most cases low. ${ }^{2,5,6,13,14,18-20,29}$ Multiple factors alone or in combination were suggested as contributors to the reduction of the seminal quality including stasis of prostatic fluid, testicular hyperthermia, recurrent urinary tract infections, abnormal testicular histology, possible changes in the hypothalamic-pituitary-testicular axis, possible anti sperm antibodies, chronic long-term use of various medications, urinary catheter and lubricant composition, an increased number of $\mathrm{WBC}$ in semen, and the type of bladder management. ${ }^{1,2,7,18,30-32}$ There might be an effect of the heat and electric current generated by EEJ itself. ${ }^{33}$ Further studies to elucidate the cause 


\begin{tabular}{|c|c|c|c|c|c|c|c|c|c|c|}
\hline \multicolumn{2}{|c|}{$\begin{array}{c}\text { Subject } \\
\text { No. Initials }\end{array}$} & & \multicolumn{8}{|c|}{ Number of trial, type of inssemination and result } \\
\hline 1 & NB & IUI-failed & IUI-failed & $\begin{array}{l}\text { IUI } \\
\text { Daughter }\end{array}$ & & & & & & \\
\hline 2 & GR & ICSI-failed & ICSI-failed & ICSI-failed & $\begin{array}{l}\text { ICSI } \\
\text { Abortion }\end{array}$ & ICSI-failed & $\begin{array}{l}\text { ICSI } \\
\text { Triplets }\end{array}$ & & & \\
\hline 3 & $\mathrm{BD}$ & ICSI-failed & ICSI-failed & ICSI-failed & ICSI-failed & ICSI-failed & $\begin{array}{l}\text { ICSI } \\
\text { Son }\end{array}$ & & & \\
\hline 4 & HS & ICSI-failed & ICSI-failed & ICSI-failed & ICSI-failed & $\begin{array}{l}\text { ICSI } \\
\text { Daughter }\end{array}$ & & & & \\
\hline 5 & LS & IUI-failed & ICSI-failed & ICSI-failed & ICSI-failed & $\begin{array}{l}\text { ICSI } \\
\text { Twins }\end{array}$ & ICSI-failed & ICSI-failed & $\begin{array}{l}\text { ICSI } \\
\text { Son }\end{array}$ & \\
\hline 6 & $\mathrm{KS}$ & $\begin{array}{l}\text { IUI } \\
\text { Abortion }\end{array}$ & $\begin{array}{l}\text { IUI } \\
\text { twins }\end{array}$ & & & & & & & \\
\hline $\begin{array}{l}7 \\
8\end{array}$ & $\begin{array}{l}\text { AA } \\
\text { HT }\end{array}$ & $\begin{array}{l}\text { IUI-failed } \\
\text { ICSI } \\
\text { Twins }\end{array}$ & IUI-failed & ICSI-failed & ICSI-failed & ICSI-failed & ICSI-failed & ICSI-failed & & \\
\hline 9 & GO & ICSI-failed & ICSI-failed & ICSI-failed & & & & & & \\
\hline 10 & $\mathrm{MZ}$ & IUI-failed & IUI-failed & ICSI-failed & ICSI-failed & $\begin{array}{l}\text { ICSI } \\
\text { Abortion }\end{array}$ & ICSI-failed & $\begin{array}{l}\text { ICSI } \\
\text { Abortion }\end{array}$ & ICSI-failed & $\begin{array}{l}\text { ICSI } \\
\text { Twins }\end{array}$ \\
\hline 11 & $\mathrm{AO}$ & ICSI-failed & ICSI-failed & $\begin{array}{l}\text { ICSI } \\
\text { Daughter }\end{array}$ & & & & & & \\
\hline 12 & $\mathrm{HH}$ & $\begin{array}{l}\text { IUI } \\
\text { Son }\end{array}$ & & & & & & & & \\
\hline 13 & VY & ICSI-failed & $\begin{array}{l}\text { ICSI } \\
\text { Daughter }\end{array}$ & & & & & & & \\
\hline 14 & NI & IUI-failed & IUI-failed & IUI-failed & IUI-failed & & & & & \\
\hline 15 & $\mathrm{AE}$ & IUI-failed & IUI-failed & IUI-failed & ICSI-failed & $\begin{array}{l}\text { ICSI } \\
\text { Twins }\end{array}$ & & & & \\
\hline 16 & FE & IUI-failed & $\begin{array}{l}\text { IUI } \\
\text { Daughter }\end{array}$ & & & & & & & \\
\hline 17 & SI & IUI-failed & IUI-failed & IUI-failed & ICSI-failed & & & & & \\
\hline 18 & $\mathrm{YO}$ & IUI-failed & ICSI-failed & ICSI-failed & $\begin{array}{l}\text { ICSI } \\
\text { Daughter }\end{array}$ & & & & & \\
\hline 19 & SA & IUI-failed & IUI-failed & IUI-failed & ICSI-failed & ICSI-failed & $\begin{array}{l}\text { ICSI } \\
\text { Daughter }\end{array}$ & ICSI-failed & ICSI-failed & \\
\hline 20 & KI & IUI-failed & ICSI-failed & ICSI-failed & & & & & & \\
\hline 21 & YE & IUI-failed & IUI-failed & IUI-failed & ICSI-failed & ICSI-failed & ICSI-failed & ICSI-failed & ICSI-failed & ICSI-failed \\
\hline 22 & RY & IUI-failed & IUI-failed & & & & & & & \\
\hline 23 & VS & $\begin{array}{l}\text { ICSI } \\
\text { Son }\end{array}$ & & & & & & & & \\
\hline 24 & GS & ICSI-failed & & & & & & & & \\
\hline 25 & $\mathrm{LN}$ & $\begin{array}{l}\text { ICSI } \\
\text { Son }\end{array}$ & & & & & & & & \\
\hline 26 & SM & ICSI-failed & $\begin{array}{l}\text { ICSI } \\
\text { Daughter }\end{array}$ & & & & & & & \\
\hline
\end{tabular}

Table 5 Comparison of reproductive techniques to number of successful couples and pregnancy rate

\begin{tabular}{lccc}
\hline & IUI & IVF/ICSI & Total \\
\hline No. couples & 15 & 20 & 26 \\
No. cycles & 33 & 68 & 101 \\
No. pregnancies & 5 & 18 & 23 \\
No. births & 3 & 14 & 17 \\
No. ongoing pregnancies & 1 & 1 & 2 \\
No. abortions & 1 & 3 & 4 \\
No. of live births & 4 & 19 & 23 \\
$\%$ Pregnancy rate/couple & 33.3 & $70^{\mathrm{a}}$ & $69.2^{\mathrm{a}}$ \\
\hline
\end{tabular}

${ }^{\mathrm{a}}$ One couple had two pregnancies of the low motility, which serves as a major obstacle in obtaining pregnancy, may improve pregnancy rates. Fortunately, the development of assisted reproductive techniques have helped to overcome this obstacle. ${ }^{34}$

The significant difference between the better semen parameters of the antegrade rather than retrograde ejaculate, might be explained by the fact that the former semen is not contaminated with urine and is 'fresher'. ${ }^{35}$ There was no significant improvement concerning sperm quality parameters after repeated stimulations.

A relationship between injury type, level and severity of the injury and between the patient's response rate was not found, although the population 
is not big enough to draw conclusions. Assuming that other factors are equal, it would seem that the duration of injury is not predictive of a successful EEJ or the quality of the ejaculates. One individual with an injury preceding EEJ by 38 years, since he was 6 years old, has achieved a live birth.

Although penile vibratory stimulation is used in many centers as first line choice in patients with lesions above T10, ${ }^{12,36}$ EEJ is still considered as a safe and efficient option. According to our results, ejaculate was obtained in all patients, approximately $54 \%$ of SCIP have semen of sufficient quality to use in IUI, and almost $90 \%$ have sufficient semen for use in IVF/ ICSI. These numbers are usually much higher than those reported with other methods. Side effects were minor in nature and encountered only in 16 patients, including abdominal pain or spasm, elevated blood pressure, increased spasm, and one case of syncope. Those side effects resolved after withdrawal of the stimulation without any treatment. We have not encountered a complication of $\mathrm{AD}$ and atrial fibrillation. ${ }^{37}$

The first reported pregnancy after EEJ was made by Thomas and associates ${ }^{15}$ in 1975 . The first healthy live birth from EEJ was documented in 1978, after cervical inseminations. ${ }^{17}$ Since then, the conception rate of SCIP following in conjunction with IUI or IVF/ICSI consists mainly of anecdotal case reports and case series. $^{8-10,14,20,24,25}$ The present study, as well as other studies, demonstrates clearly the improvement in the fertility results during the last decade.

In our opinion, the most encouraging results in our series stems from few major facts-our disabled persons and their families' demands consistently to have children in order to improve their family well being, as part of the psycho-social characteristics of the Jewish and Arab people; a dedicated, well trained and equipped team, which is still not under any financial restrictions in using sophisticated and modern assisted reproductive techniques; the 'directness' characteristic of the patients-physicians relationship.

In our center we put an emphasis on close and multidisciplinary comprehensive follow-up, so the patients are treated and rehabilitated at our center as well as performing long term follow-up, which includes sexual and fertility counselling. The country is small and our center, which serves as the national SCI center, is easily accessible from everywhere. Our fertility team approach model consists of close cooperation between the patients and their families, physiatrist, andrologist, gynecologist, sperm-processing laboratory specialist, nurses, and psycho-social staff. We believe this study might encourage the continued development of properly-funded spinal fertility services around the world, adopting a similar model.

The high percentage of pregnancies implies that despite the typically poor sperm motility noted in EEJ, rectal probe EEJ combined with IUI or IVF/ICSI and performed by teamwork, is an efficient and safe treatment of male infertility in the SCI population. ${ }^{34}$
Recent encouraging results of the PVS method $^{35,38-40}$ lead us to use this method parallel to the EEJ method. At present we prefer to use the PVS as first line choice treatment in SCIP with a lesion above T10, ${ }^{12}$ and to use EEJ in cases of failure. Accordingly, the regular clinical and domestic use of PVS is gaining awareness among patients and carers.

\section{References}

1 Ditunno JF, Formal CS. Current concepts: chronic spinal cord injury. NEJM 1994; 330: $550-556$.

2 Linsenmeyer TA. Sexual function and infertility following spinal cord injury. Phys Med Rehabil Clin North Am 2000; 11: 141 - 156.

3 Monga M, Bernie J, Rajasekaran M. Male infertility and erectile dysfunction in spinal cord injury: a review. Arch Phys Med Rehabil 1999; 80: $1331-1339$.

4 Bors E, Cornarr E. Neurological disturbances of sexual function with special reference to 529 patients with spinal cord injury. Urol Surv 1960; 10: $191-222$.

5 Sedor JF, Hirsch IH. Evaluation of sperm morphology of electroejaculates of spinal cord-injured men by strict criteria. Fertil Steril 1995; 63: 1125 - 1127.

6 Denjil J et al. Functional characteristics of sperm obtained by electroejaculation. J Urol 1992; 147: 69-72.

$7 \mathrm{Ohl}$ DA et al. Fertility of spinal cord injured males: effect of genitourinary infection and bladder management on results of electroejaculation. J Am Parapleg Soc 1992; 15: 53-59.

8 Otani T, Konada A, Takita T. A paraplegic fathering a child after an intrathecal injection of neostigmine. Paraplegia 1983; 23: 32 37.

9 Chapelle PA et al. Treatment of anejaculation in the total paraplegic by subcutaneous injection of physostigmine. Paraplegia $1983 ; 21: 30-36$.

10 Hovatto O, von Smitten K. Sperm aspiration from vas deferens and in-vitro fertilization in cases of non-treatable anejaculation. Hum Reprod 1993; 8: 1689 - 1691.

11 Brindley GS, Sauerwern D, Henry WF. Hypogastric plexus stimulators for obtaining semen from paraplegic men. $\mathrm{Br} \mathrm{J} \mathrm{Hrol}$ 1989; 64: 72 .

12 Brindley GS. Reflex ejaculation under vibratory stimulation in paraplegic men. Paraplegia 1981; 19: 299-302.

13 Sarkarati M, Rossier AB, Fam BA. Experience in vibratory and electro-ejaculation techniques in spinal cord injury patients: a preliminary report. $J$ Urol 1987; 138: 59-62.

14 Nehra A et al. Vibratory stimulation and rectal probe electroejaculation as therapy for patients with spinal cord injury: semen parameters and pregnancy rates. J Urol 1996; 155: $554-559$.

15 Thomas RJS, McLeish G, McDonald JA. Electroejaculation of the paraplegic male followed by pregnancy. Med J Aust 1975; 2: 798.

16 Bennett CJ et al. Sexual dysfunction and electroejaculation in men with spinal cord injury. (Review). J Urol 1988; 139: 453.

17 Francois $\mathrm{N}$ et al. Electroejaculation of a complete paraplegic followed by pregnancy. Paraplegia 1978; 16: 248.

18 Chung PH et al. Assisted fertility using electroejaculation in men with spinal cord injury - a review of literature. Fertil Steril 1995; 64: $1-9$.

19 Buch JP, Zorn BH. Evaluation and treatment of infertility in spinal cord injured men through rectal probe electroejaculation. J Urol 1993; 149: 1350-1354.

20 Bennett CJ et al. Electroejaculation of paraplegic males followed by pregnancies. Fert Steril 1987; 48: 1070-1072.

21 Chung $\mathrm{PH}$ et al. Electroejaculation and assisted reproductive techniques for anejaculatory infertility. Obstet Gynecol 1996; 87: $22-26$.

22 Schatte EC et al. Treatment of infertility due to anejaculation in the male with electroejaculation and intracytoplasmic sperm injection. J Urol 2000; 163: $1717-1720$. 
23 Raymond CA. New use for old method of inducing ejaculation may give hope of fatherhood to some spinal cord injured men. JAMA 1987; 258: $743-744$.

24 Hultling $\mathrm{C}$ et al. Assisted ejaculation combined with in vitro fertilization: an effective technique treating male infertility due to spinal cord injury. Paraplegia 1994; 32: 463-467.

25 Leeton J, Yates C, Rawicki B. Successful pregnancy using known donor oocytes fertilized in vitro by spermatozoa obtained by electro-ejaculation from a quadriplegic husband. Hum Reprod 1991; 6: $384-385$.

26 Heruti RJ, Ohry A. The rehabilitation team work - a commentary. Am J Phys Med Rehabil 1995; 74: 466-468.

27 Chen D, Ling EA, Jeyendran RS. Semen extenders to salvage ejaculate in a retrograde ejaculate environment: a potential use in spinal cord-injured men. Arch Phys Med Rehabil 1995; 76: 446449.

28 World Health Organization. WHO Laboratory Manual for the Examination of Human Semen and Semen-Cervical Mucus Interaction. Cambridge, Cambridge University Press, 1987.

29 Ohl DA et al. Predictors of success in electroejaculation of spinal cord injured men. J Urol 1993; 149: $1350-1354$.

30 Siosteen A, Steen Y, Forssman L, Sullivan L. Auto-immunity to spermatozoa and quality of semen in men with spinal cord injury. Int J Fertil 1993; 38: 117-122.

31 Elliott SP et al. Testis biopsy findings in the spinal cord injured patient. J Urol 2000; 163: $792-795$.

32 Aird IA et al. Leukocytes in semen from men with spinal cord injuries. Fertil Steril 1999; 72: $97-103$.
33 Linsenmeyer T, Wilmot C, Anderson RU. The effects of the electroejaculation procedure on sperm motility. Paraplegia 1989; 27: $465-469$

34 Rutkowski SB et al. A comprehensive approach to the management of male infertility following spinal cord injury. Spinal Cord 1999; 37: $508-514$.

35 Chen D, Hartwig DM, Roth EJ. Comparison of sperm quantity and quality in antegrade vs. retrograde ejaculates obtained by vibratory penile stimulation in males with spinal cord injury. $A m$ J Phys Med Rehabil 1999; 78: 46-51.

36 Brackett NL. Semen retrieval by penile vibratory stimulation in men with spinal cord injury. Hum Reprod Update 1999; 5: 216 222.

37 Scheutzow MH, Bockenek WL. An unusual complication during electroejaculation in an individual with tetraplegia. J Spinal Cord Med 2000; 23: $28-30$

38 Brackett NL et al. An analysis of 653 trials of penile vibratory stimulations in men with spinal cord injury. J Urol 1998; 159: $1931-1934$.

39 Ohl DA, Menge AC, Sonksen J. Penile vibratory stimulation in spinal cord injured men: optimized vibration parameters and prognostic factors. Arch Phys Med Rehab 1996; 77: 903-905.

40 Ohl DA et al. Electroejaculation versus vibratory stimulation in spinal cord injured men: sperm quality and patient preference. $J$ Urol 1997; 157: $2147-2149$. 